\title{
Cytotoxicity of chlorhexidine and neem extract on cultured human gingival fibroblasts through fluorescence-activated cell sorting analysis : An in-vitro study
}

\author{
Umesh Pratap Verma ${ }^{1}$, Abhaya Gupta ${ }^{1}$, Rakesh Kumar Yadav ${ }^{2}$, Rini Tiwari ${ }^{1}$, \\ Ramesh Sharma ${ }^{3}$, Anil Kumar Balapure ${ }^{3}$
}

Correspondence: Dr. Umesh Pratap Verma Email: umeshpratapverma@kgmcindia.edu

\begin{abstract}
'Department of Periodontology, Faculty of Dental Sciences, King George's Medical University, Lucknow, Uttar Pradesh, India,

2Department of Conservative and Endodontics, Faculty of Dental Sciences, King George's Medical University, Lucknow, Uttar Pradesh, India,

${ }^{3}$ Department of Biochemistry, CSIR-CDRI, Lucknow, Uttar Pradesh, India
\end{abstract}

\section{ABSTRACT}

Objective: To assess the influence of chlorhexidine (CHX), neem vehicle control (NVC), and neem extract (NE) on cultured human gingival fibroblasts (hGFs) using 3-(4,5-dimethylthiazol-2-yl)-2,5-diphenyltetrazolium bromide (MTT) assay and fluorescence-activated cell sorting (FACS) analysis. Materials and Methods: Fibroblasts were derived from healthy gingival biopsy specimens harvested aseptically. The effects of CHX, NVC, and NE were evaluated on cultured hGFs through FACS and MTT assay. Results: MTT assay with hGFs indicated altered morphology with maximum cell death at $10 \%$ CHX, while NVC and NE showed similar results at a concentration of $75 \%$ and above. On FACS analysis, beyond $1 \%$, CHX adversely affected the cell cycle phase distribution whereas NE exerted a detrimental effect only at 100\%. Moreover, both with NVC and NE cells were well differentiated in all the three phases of the cell cycle, with distinction getting lost at $50 \%$ to finally causing cell death at $100 \%$. Conclusions: $\mathrm{CHX}$ beyond $1 \%$ concentration exhibited a toxic effect on hGFs at 1, 5, and 15 min time exposure. However, NE did not adversely affect the fibroblasts even up to $50 \%$ concentration showing a less toxic effect in comparison with CHX on these cells. The cytoprotective and oral friendly quality of NE emphaisze the superiority of NE over CHX.

Key words: 3-(4,5-dimethylthiazol-2-yl)-2,5-diphenyltetrazolium bromide assay, chlorhexidine, cytotoxicity, fluorescence-activated cell sorting analysis, human gingival fibroblasts, neem extract

\section{INTRODUCTION}

Periodontal disease is initiated by microbial plaque. Various mechanical methods and chemical agents are used to prevent the formation and deposition of microbial plaque. ${ }^{[1]}$ The chemical agents such as

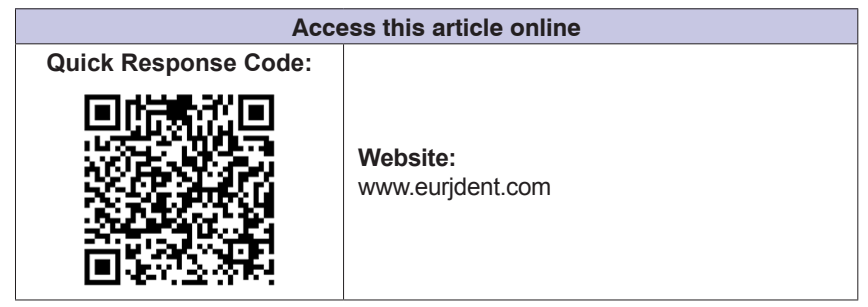

This is an open access journal, and articles are distributed under the terms of the Creative Commons Attribution-NonCommercial-ShareAlike 4.0 License, which allows others to remix, tweak, and build upon the work non-commercially, as long as appropriate credit is given and the new creations are licensed under the identical terms.

For reprints contact: reprints@medknow.com

How to cite this article: Verma UP, Gupta A, Yadav RK, Tiwari R,
Sharma R, Balapure AK. Cytotoxicity of chlorhexidine and neem extract
on cultured human gingival fibroblasts through fluorescence-activated
cell sorting analysis : An in-vitro study. Eur J Dent 2018;12:344-9.
DOI: 10.4103/ejd.ejd_149_17 
chlorhexidine ( $\mathrm{CHX}$ ) and povidone iodine have been used in the form of mouth rinse and subgingival irrigating solution. ${ }^{[2]}$ In addition to chemical agents, some herbal preparations have also been used for the inhibition of plaque-like Sanguinarine ${ }^{[2]}$ and Neem. ${ }^{[3]}$ The human gingival fibroblasts (hGFs) are very important cells of periodontal connective tissue that helps in wound healing. The present study focuses on effects of neem and CHX on cultured hGFs through 3-(4,5-dimethylthiazol-2-yl)-2,5-diphenyltetrazolium bromide (MTT) assay and fluorescence-activated cell sorting (FACS) analysis.

\section{MATERIALS AND METHODS}

This study was conducted at the Department of Periodontics, Faculty of Dental Sciences, King George's Medical University, Lucknow, with permission of the Institutional Ethics Committee in collaboration with CSIR-CDRI.

Preparation of neem extract (NE): The neem leaves and bark were collected from a local area of Lucknow and were shade dried and grounded into fine powder. The samples were then extracted three times with methanol using Polytron Homogen (Kinematica, Pt 6100, Switzerland). The extracts thus obtained were concentrated separately using rotary evaporator (Buchi type) and portioned with hexane by the process of liquid phase extraction to eliminate fats and oils. The obtained methanolic fraction was again portioned with ethyl acetate and water to remove sugars, protein, and carbohydrates. The ethyl acetate fraction thus obtained was concentrated and weighed. The formulations used for this study were prepared using $0.5 \%$ ethyl acetate fractions of neem leaves and bark in 15\% edible grade ethanol(vehicle control). \#(CSIR-NBRI.Lucknow,India")

Isolation of cell culture: The hGF cell lines were routinely maintained in the Tissue and Cell Culture Laboratory, CSIR-CDRI, Lucknow.

Experimental design for $\mathrm{CHX}$, neem vehicle control (NVC), and NE exposure to gingival fibroblasts cultures: CHX mouthwash $(0.2 \%) *(I C P A$, Ankleshwar, Gujrat, India), NVC, and NE were regarded as $100 \%$ solutions and were diluted to $0.1 \%, 1.0 \%, 10 \%, 25 \%, 50 \%$, and $75 \%$ for experimental purposes. The $100 \%$ solution/extract with the help of $\mathrm{NaOH}(1 \mathrm{~N})$ was first adjusted to $\mathrm{pH}$ 7.4. This was treated as stock solution and diluted as per requirement in Dulbecco's Modified Eagle Medium
(DMEM) (pH 7.4), $\mathrm{pH}$ 7.4. The $\mathrm{pH}$ of all solutions was ascertained to be 7.4 before use.

From a freshly trypsinized flask, $5 \times 10^{4}$ cells were plated in 12-welled tissue culture plates and incubated for $24 \mathrm{~h}$ at $37^{\circ} \mathrm{C}$ in a humidified $\mathrm{CO}_{2}$ incubator. Subsequently, the cells were exposed with different concentrations of CHX mouthwash, NVC, and NE for $1 \mathrm{~min}, 5 \mathrm{~min}$, and $15 \mathrm{~min}$ at $37^{\circ} \mathrm{C}$. Finally, the cells were incubated at $37^{\circ} \mathrm{C}$ in a $\mathrm{CO}_{2}$ incubator for $48 \mathrm{~h}$. The cells were visualized under phase contrast microscope with $35 \mathrm{~mm}$ camera at $\times 100$ and $\times 200$ magnifications using Kodak Color $\times 400$ ASA photo film.

MTT assay: In the freshly prepared culture plates after incubation for $24 \mathrm{~h}$ at $37^{\circ} \mathrm{C}, 20 \mu \mathrm{l}$ of MTT $(5 \mu \mathrm{g} / \mathrm{ml})$ was added per well and then the cultures were incubated further for $4-6 \mathrm{~h}$.

Thereafter, the media was aspirated and the resultant formed crystals were dissolved in $200 \mu$ l Dimethyl sulfoxide (DMSO). The plate was read at $550 \mathrm{~nm}$ through ELISA plate reader. ${ }^{[4]}$

FACS analysis: Logarithmically growing gingival fibroblast cells were harvested with $0.05 \%$ trypsin-EDTA solution. $0.2 \times 10^{6}$ cells/well were plated in 6-welled plates for $24 \mathrm{~h}$ in DMEM. Ligands were added at $1 \%-100 \%$ doses for $5 \mathrm{~min}$ and cells harvested by trypsinization were washed with chilled phosphate-buffered saline (PBS) and centrifuged at $100 \mathrm{rpm}$ for $10 \mathrm{~min}$ at $4^{\circ} \mathrm{C}$. Cells were permeabilized with $70 \%$ chilled ethanol for $30 \mathrm{~min}$ at $4^{\circ} \mathrm{C}$. The pellet was resuspended in PBS containing propidium iodide (PI) $(40 \mu \mathrm{g} / \mathrm{ml})$ and analyzed by flow cytometry for cell cycle study. ${ }^{[5]}$

Mean, standard deviation, and standard error were calculated as per the standard formulae and the significance of changes was tested using paired " $t-$ " test. ${ }^{[6]}$

\section{RESULTS}

The cell cultures were exposed to CHX mouthwash, NVC, and NE at a concentration of $0.1 \%, 1.0 \%, 10 \%$,

\begin{tabular}{|c|c|c|}
\hline Mouthwash/extract & Prerinsing $\mathrm{pH}$ & Postrinsing $\mathrm{pH}$ \\
\hline $\mathrm{CHX}$ & 5.0 & 6.9 \\
\hline NVC & 6.5 & 7.4 \\
\hline NE & 6.8 & 7.1 \\
\hline
\end{tabular}


$25 \%, 50 \%, 75 \%$, and $100 \%$ for $1 \mathrm{~min}, 5 \mathrm{~min}$, and $15 \mathrm{~min}$ duration for MTT and FACS analysis.

Table 1 depicts the $\mathrm{pH}$ of $\mathrm{CHX}$, NVC, and NE pre- and postrinsing for 20-25 s. Tables 2-7 show optical density of viable hGF using MTT assay in the presence of the above solutions. FACS analysis for changes in the membrane permeability and cell cycle in hGF for 5 minute" needs deletion.

In CHX-treated groups, the majority of the cells were found to be in " $\mathrm{G}_{0} / \mathrm{G}_{1}$ " phase with very few cells in " $S$ " phase and $\mathrm{G}_{2} / \mathrm{M}$ phase of cell cycle at $1 \%$ concentration of $\mathrm{CHX}$. However, at $25 \%$ concentration, the cells plateau into single continuous indistinct cycle, denoting the cytotoxicity of the mouthwash to die out at $50 \%$ and $100 \%$ concentration.

In NVC-treated group, at $1 \%$ concentration, it causes damage to the cell membrane and $25 \%-50 \%$ concentration shows a decrease in the number of cells in $G_{0} / G_{1}$ phase, but at $100 \%$ concentration, the cells do not show much distinction between various phases despite remaining viable. Briefly, the cells very well tolerated the vehicle control up to $50 \%$ concentration beyond which the toxicity was seen up to $100 \%$ concentration.

In NE-treated group, at $1 \%$ and $25 \%$ concentration, very mild effect was observed on the cell membrane with cells dying at a concentration of $50 \%$ and $100 \%$ [Figure 1].

\section{DISCUSSION}

In the present study, cytotoxicity of different concentrations of NE was assessed on freshly developed hGF cell line and compared with CHX as control using MTT assay. Further cell membrane permeability, DNA perturbations, and effects on different phases of cell cycle on mouthwash exposure were analyzed by FACS analysis. MTT assay is a cytotoxicity assay that measures the mitochondrial activity of live cells. Damour et al. ${ }^{[7]}$ have also observed the cytotoxic effect on cultured human fibroblasts using MTT assay.

The cytotoxicity assay shows that $10 \%$ concentration of $\mathrm{CHX}$ is responsible for maximum cell death as indicated in Table 2 whereas NVC showed the same result at $100 \%$ concentration [Table 3]. NE showed maximum cytotoxicity on hGF at concentration of $75 \%$ as indicated in Table 4 . From the above data, it is evident that the CHX is more cytotoxic as compared to NVC and NE, which is evaluated further in next parameter.

The cytotoxic effect of $\mathrm{CHX}$ on cultured human periodontal ligament and hGF by Chang et al. ${ }^{[8]}$ and Rajabalian et al. ${ }^{[9]}$ is in agreement with the findings

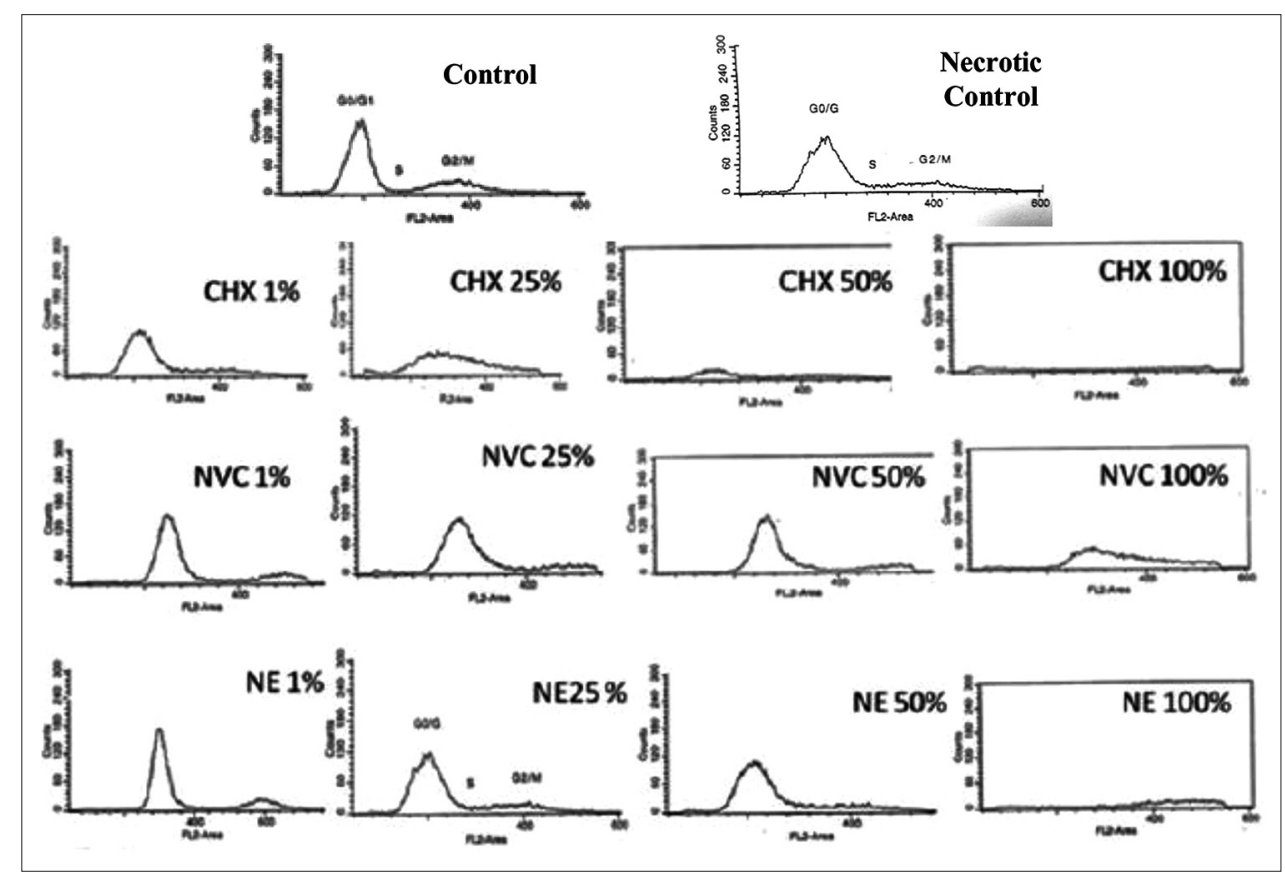

Figure 1: Flow cytometry analysis for cell cycle studies on human gingival fibroblasts versus the ligands was conducted. After exposing the cells with different ligands at $1 \%, 25 \%, 50 \%$, and $100 \%$ doses for $1 \mathrm{~min}$, the cells were analyzed by fluorescence-activated cell sorting for cell cycle. Control depict cells in all the three phases 


\begin{tabular}{|c|c|c|c|}
\hline Concentration (\%) & $1 \mathrm{~min}$ & $5 \mathrm{~min}$ & $15 \min$ \\
\hline 0.1 & $0.856 \pm 0.032$ & $0.729 \pm 0.028$ & $0.793 \pm 0.040$ \\
\hline 1.0 & $0.771 \pm 0.057$ & $0.754 \pm 0.038$ & $0.705 \pm 0.038$ \\
\hline 10 & $0.323 \pm 0.004$ & $0.011 \pm 0.005$ & $0.013 \pm 0.003$ \\
\hline 25 & $0.098 \pm 0.003$ & $0.019 \pm 0.002$ & $0.015 \pm 0.004$ \\
\hline 50 & $0.110 \pm 0.007$ & $0.013 \pm 0.004$ & $0.015 \pm 0.002$ \\
\hline 75 & $0.108 \pm 0.006$ & $0.018 \pm 0.008$ & $0.023 \pm 0.006$ \\
\hline 100 & $0.095 \pm 0.001$ & $0.018 \pm 0.006$ & $0.034 \pm 0.008$ \\
\hline
\end{tabular}

\begin{tabular}{|c|c|c|c|}
\hline Concentration (\%) & $1 \mathrm{~min}$ & $5 \mathrm{~min}$ & $15 \mathrm{~min}$ \\
\hline 0.1 & $0.760 \pm 0.093$ & $0.743 \pm 0.085$ & $0.884 \pm 0.073$ \\
\hline 1.0 & $0.869 \pm 0.099$ & $0.897 \pm 0.120$ & $0.815 \pm 0.003$ \\
\hline 10 & $0.739 \pm 0.048$ & $0.810 \pm 0.091$ & $0.850 \pm 0.115$ \\
\hline 25 & $0.800 \pm 0.035$ & $0.960 \pm 0.280$ & $0.578 \pm 0.414$ \\
\hline 50 & $0.814 \pm 0.068$ & $0.864 \pm 0.102$ & $0.852 \pm 0.004$ \\
\hline 75 & $0.682 \pm 0.237$ & $0.554 \pm 0.121$ & $0.520 \pm 0.005$ \\
\hline 100 & $0.093 \pm 0.012$ & $0.107 \pm 0.001$ & $0.093 \pm 0.005$ \\
\hline
\end{tabular}

\begin{tabular}{|c|c|c|c|}
\hline Concentration (\%) & $1 \mathrm{~min}$ & $5 \mathrm{~min}$ & $15 \mathrm{~min}$ \\
\hline 0.1 & $0.863 \pm 0.037$ & $0.757 \pm 0.052$ & $0.923 \pm 0.041$ \\
\hline 1.0 & $0.789 \pm 0.079$ & $0.877 \pm 0.041$ & $0.926 \pm 0.035$ \\
\hline 10 & $0.778 \pm 0.011$ & $0.614 \pm 0.052$ & $0.518 \pm 0.029$ \\
\hline 25 & $0.715 \pm 0.031$ & $0.520 \pm 0.030$ & $0.473 \pm 0.016$ \\
\hline 50 & $0.572 \pm 0.030$ & $0.486 \pm 0.049$ & $0.408 \pm 0.012$ \\
\hline 75 & $0.261 \pm 0.030$ & $0.028 \pm 0.000$ & $0.023 \pm 0.005$ \\
\hline 100 & $0.013 \pm 0.002$ & $0.015 \pm 0.001$ & $0.007 \pm 0.003$ \\
\hline
\end{tabular}

\begin{tabular}{|c|c|c|c|}
\hline \multirow{2}{*}{$\begin{array}{l}\text { Concentration } \\
\text { (\%) }\end{array}$} & \multicolumn{3}{|c|}{$t$} \\
\hline & $\begin{array}{c}1 \mathrm{~min} \text { versus } \\
5 \mathrm{~min}\end{array}$ & $\begin{array}{c}1 \mathrm{~min} \text { versus } \\
15 \mathrm{~min}\end{array}$ & $\begin{array}{c}5 \text { min versus } \\
15 \mathrm{~min}\end{array}$ \\
\hline 0.1 & $3.186^{*}$ & 1.403 & 1.287 \\
\hline 1.0 & 0.242 & 0.949 & 0.905 \\
\hline 10 & $48.016^{\star * *}$ & $63.123^{\star * *}$ & 0.237 \\
\hline 25 & $23.383^{* \star *}$ & $15.977^{\star * *}$ & 0.875 \\
\hline 50 & $11.838^{* \star *}$ & $13.231^{* * *}$ & 0.279 \\
\hline 75 & $9.522^{* *}$ & $10.439^{* * *}$ & 0.553 \\
\hline 100 & $12.694^{* * *}$ & $7.141^{\text {** }}$ & 1.530 \\
\hline
\end{tabular}

of the present study. Treatment time comparison of the response of fibroblasts to different concentrations of CHX (Table.5),NVC(Table.6) and NE(Table.7) has been done utilizing two parametrs i.e concentration $(\%)$ of the different agents and different time periods combinations like 1 minute Vs 5 minute, 1 minute Vs 15 minute and 5 minute Vs 15 minute revealing critically useful information.

Based on the aforesaid discussion on the cytotoxicity assay and analysis of the three mouthwashes in question, i.e., $\mathrm{CHX}, \mathrm{NVC}$, and $\mathrm{NE}$, it was decided to employ FACS parameters to the exposed fibroblasts. The time period of exposure was narrowed down to $5 \mathrm{~min}$, and the concentrations evaluated were $1 \%$, $25 \%, 50 \%$, and $100 \%$ since $1 \mathrm{~min}$ is the lower limit and $15 \mathrm{~min}$ is the upper limit of exposure in our studies.

As explained earlier, the flow data initially essentially contains two controls, one being the untreated fibroblasts (normal control) and the second being the necrotic control where fibroblasts necrosed on freezing-thawing in liquid nitrogen. This is the standard protocol since necrosis causes damage to the plasma membrane thereby allowing the assay dye Propidium iodide (PI) to penetrate the cell and bind to DNA. In Figure.1 the FL area provide a measure of fluorescence uptake with peaks denoting different phases of cell cycle. There is a dose dependent increase in PI fluorescent probe uptake from 1\% to 50\% CHX concentration with decline seen at $100 \%$ of $\mathrm{CHX}$ concentration..

The observance of florescence at $100 \% \mathrm{CHX}$ concentration as shown in Figure 1 is possibly due to the fixing of cells at the highest concentration and PI binding to the DNA-like material. Thus, it can be concluded that even $1 \% \mathrm{CHX}$ exposure to the fibroblasts adversely affects the plasma membrane which increases proportionally until $50 \%$ concentration.

The results of fibroblasts membrane damage on exposure to $\mathrm{CHX}$ as previously discussed were carried downstream to the adverse changes in the cell cycle where $1 \%$ exposure showed adverse effects in all the phases as compared to normal control. Phases $\mathrm{G}_{0} / \mathrm{G}_{1}, \mathrm{~S}$, and $\mathrm{G}_{2} / \mathrm{M}$ show the toxic effects with reduced distribution of cells in each. The cell cycles were progressively affected until $100 \%$ CHX concentration.

The PI uptake at $1 \%$ and $25 \%$ of NVC exposure to fibroblasts was found to be similar to that observed in the ecrotic control rather than normal control [Figure 1]. At 50\% NVC, the PI uptake declined 


\begin{tabular}{|c|c|c|c|}
\hline \multicolumn{4}{|c|}{$\begin{array}{l}\text { Table 6: Treatment time comparison } \\
\text { of neem vehicle control treatment to } \\
\text { fibroblasts at different concentrations using } \\
3-(4,5-\text { dimethylthiazol-2-yl)-2,5-diphenyltetrazolium } \\
\text { bromide assay }\end{array}$} \\
\hline \multirow{2}{*}{$\begin{array}{l}\text { Concentration } \\
(\%)\end{array}$} & \multicolumn{3}{|c|}{$t$} \\
\hline & $\begin{array}{l}1 \mathrm{~min} \text { versus } \\
5 \mathrm{~min}\end{array}$ & $\begin{array}{c}1 \mathrm{~min} \text { versus } \\
15 \mathrm{~min}\end{array}$ & $\begin{array}{c}5 \mathrm{~min} \text { versus } \\
15 \mathrm{~min}\end{array}$ \\
\hline 0.1 & 0.234 & 1.819 & 2.180 \\
\hline 1.0 & 0.315 & 0.889 & 1.136 \\
\hline 10 & 1.188 & 1.535 & 0.472 \\
\hline 25 & 0.979 & 0.923 & 1.320 \\
\hline 50 & 0.700 & 0.835 & 0.185 \\
\hline 75 & $2.793^{*}$ & $4.932^{* *}$ & 0.438 \\
\hline 100 & 1.710 & 0.086 & 2.561 \\
\hline
\end{tabular}

\begin{tabular}{|c|c|c|c|}
\hline \multirow{3}{*}{$\begin{array}{l}\text { Concentration } \\
(\%)\end{array}$} & \multirow{2}{*}{\multicolumn{3}{|c|}{$t$}} \\
\hline & & & \\
\hline & $\begin{array}{c}1 \mathrm{~min} \text { versus } \\
5 \mathrm{~min}\end{array}$ & $\begin{array}{c}1 \text { min versus } \\
15 \mathrm{~min}\end{array}$ & $\begin{array}{c}5 \mathrm{~min} \text { versus } \\
15 \mathrm{~min}\end{array}$ \\
\hline 0.1 & 1.666 & 1.083 & 2.519 \\
\hline 1.0 & 0.992 & 1.599 & 0.919 \\
\hline 10 & $3.102^{*}$ & $8.340^{* *}$ & 1.607 \\
\hline 25 & $4.518^{*}$ & $6.956^{\star *}$ & 1.376 \\
\hline 50 & 1.483 & $4.097^{* *}$ & 1.533 \\
\hline 75 & $7.961^{\star *}$ & $8.014^{* *}$ & 0.989 \\
\hline 100 & 1.131 & 1.268 & 2.135 \\
\hline
\end{tabular}

drastically to rise again at $100 \%$ concentration to maximal level, indicating maximum membrane changes. The results at $100 \%$ NVC exposure are akin to those witnessed with necrotic control.

Despite the fact that the plasma membrane architecture of fibroblasts changes with NVC exposure, the cells remain evenly distributed in the different phases of the cell cycle from $1 \%$ to $50 \%$ concentration of NVC. It is interesting to note the relationship between the fluorescence versus cell cycle changes. At 100\% NVC concentration, the phases, i.e., $G_{0} / G_{1}$ to $G_{2} / M$, including the $S$ phase become indistinguishable.

Comparison with $\mathrm{CHX}$ clearly indicate that even $1 \%$ concentration of CHX exposure can bring about changes in normal control making them look more like necrotic control. Further, it was inferred that upto $75 \%$ NVC was better tolerated than similar concentration of CHX as a mouth rinse. The most important mouth rinse evaluated through FACS in the present study, i.e., NE, revealed most interesting data when compared to the results obtained with $\mathrm{CHX}$ and NVC. At $1 \%$ NE exposure, although the PI uptake was slightly of a higher order, but the cell cycle data revealed that cells were more sharply distinct in all 3 phases of cell cycle than the normal control. This clearly suggested some "unknown factor" that might reside in the NE, causing the cells to withstand the slight perturbations in the fluorescence, but yet providing more crisper and distinct phases over the normal control. The results on NE are in complete disagreement over the necrotic control, suggesting its utility. As the concentration of NE is raised from $25 \%$ to $100 \%$, the PI uptake does not alter much too adverse status at $50 \%$ and $100 \%$ concentration, respectively.

\section{CONCLUSIONS}

NE, thus, exhibits the best results as compared to CHX and NVC since the last two show membrane damage even at $1 \%$ concentration. Conversely, the NE shows the cells undamaged in terms of fluorescence and improvement in cell cycle stages even over the normal control. The fact that membrane integrity is unaffected up to $50 \%$ exposure to NE, a crucial feature, makes us choose it as the best among the three mouth rinses tested.

The in vitro studies conducted here would greatly help extrapolate the situation under intact in vivo conditions that exist in a human where fibroblast interaction with other cellular components including the vasculature is crucial.

\section{Financial support and sponsorship Nil.}

\section{Conflicts of interest}

There are no conflicts of interest.

\section{REFERENCES}

1. Cline NV, Layman DL. The effects of chlorhexidine on the attachment and growth of cultured human periodontal cells. J Periodontol 1992;63:598-602.

2. Mandel ID. Chemotherapeutic agents for controlling plaque and gingivitis. J Clin Periodontol 1988;15:488-98.

3. Vanka A, Tandon S, Rao SR, Udupa N, Ramkumar P. The effect of indigenous neem Azadirachta Indica [correction of (Adirachta indica)] mouth wash on Streptococcus mutans and Lactobacilli growth. Indian J Dent Res 2001;12:133-44.

4. Tada H, Shiho O, Kuroshima K, Koyama M and Tsukamato K. An improved colorimetric assay for interleukin-2. J of Immunological methods 1986; 93: 157-165. 
5. Perry RR, Kang Y, Greaves BR. Relationship between tamoxifen-induced transforming growth factor beta 1 expression, cytostasis and apoptosis in human breast cancer cells. Br J Cancer 1995;72:1441-6.

6. Kim TK. T test as a parametric statistic. Korean J Anesthesiol 2015;68:540-6.

7. Damour O, Hua SZ, Lasne F, Villain M, Rousselle P, Collombel C, et al. Cytotoxicity evaluation of antiseptics and antibiotics on cultured human fibroblasts and keratinocytes. Burns 1992;18:479-85.
8. Chang YC, Huang FM, Tai KW, Chou MY. The effect of sodium hypochlorite and chlorhexidine on cultured human periodontal ligament cells. Oral Surg Oral Med Oral Pathol Oral Radiol Endod 2001;92:446-50

9. Rajabalian S, Mohammadi M, Mozaffari B. Cytotoxicity evaluation of persica mouthwash on cultured human and mouse cell lines in the presence and absence of fetal calf serum. Indian J Dent Res 2009;20:169-73 